\title{
Proximal Femoral Nail in Reverse Trochanteric Femoral Fractures: An Analysis of 53 Cases at One Year Follow-Up
}

\author{
Yogesh Salphale, Wasudeo Mahadeo Gadegone, Alankar Ramteke, Nirbhay Karandikar, \\ Raviraj Shinde, Prakash Lalwani \\ Department of Orthopaedics \& Traumatology, Chandrapur Multispeciality Hospital, Chandrapur, India \\ Email: yosa@aol.in
}

Received 9 June 2016; accepted 4 July 2016; published 7 July 2016

Copyright (C) 2016 by authors and Scientific Research Publishing Inc.

This work is licensed under the Creative Commons Attribution International License (CC BY).

http://creativecommons.org/licenses/by/4.0/

(c) (7) Open Access

\begin{abstract}
Treatment of reverse oblique trochanteric femoral fractures poses a lot of challenges. There have been proponents of intramedullary devices as well as extramedullary devices. We present the results of proximal femoral nailing surgery performed for reverse obliquity intertrochanteric fractures using two proximal lag screws and a nail of $250 \mathrm{~mm}$. There is prospective study of fifty three patients with AO/OTA $31 \mathrm{~A}-\mathrm{A} 3$ fractures being treated by proximal femoral nailing in our institute after seeking approval from the Hospital ethics board. The quality of the reduction, the operative time, complications and the functional status of the patients were the parameters on which the results were evaluated. The mean Harris hip score was 76.66 (range 70 - 93) and the mean Barthel activity score was 16.21 (range 12 - 20). The average surgical time was 50 minutes and the mean consolidation time was $\mathbf{1 1 . 5}$ weeks. Intramedullary nailing with proximal femoral nails seems to be a good option in the treatment of reverse obliquity intertrochanteric fractures as against the various existing options available for the management.
\end{abstract}

\section{Keywords}

Proximal Femoral Nailing, Reverse Obliquity Intertrochanteric Fractures, Intramedullary Nailing, PFN, Cephalomedullary Nail, Hip Fracture

\section{Introduction}

The incidence of fractures in the proximal femoral area has risen with the increasing numbers of elderly persons

How to cite this paper: Salphale, Y., Gadegone, W.M., Ramteke, A., Karandikar, N., Shinde, R. and Lalwani, P. (2016) Proximal Femoral Nail in Reverse Trochanteric Femoral Fractures: An Analysis of 53 Cases at One Year Follow-Up. Surgical Science, 7, 300-308. http://dx.doi.org/10.4236/ss.2016.77043 
with osteoporosis and traffic accidents in young adults. This typical bimodal pattern of injuries presents with an array of clinico radiological pictures.

Fractures about the trochanteric area are classified according to the Orthopaedic Trauma Association classification system as AO/OTA 31-A, which delineates them as extracapsular fractures of the hip. These fractures are subdivided into groups A1, A2 and A3 based on the radiological classifications. The A1 fractures are simple, two part fractures, whereas A2 fractures have multiple fragments. A3 fractures include reverse oblique and transverse fracture patterns.

There are two main types of implant available for the treatment of these fractures, namely, extramedullary and intramedullary implants [1] [2].

Many authors have reported that the extra medullary device is not suitable for AO/OTA 31-A3 reverse oblique or transverse fractures due to high incidence of fixation failures. Thus, the treatment of these unstable trochanteric femoral fractures is challenging, and clinical reports regarding intramedullary hip nailing for reverse obliquity intertrochanteric fractures are few in number [3]-[5].

The aim of the surgery is to achieve initial stability and early mobilization of the patients to avoid complications, such as deep vein thrombosis, thrombophlebitis, pulmonary embolism, urinary and lung infection and ulcers.

In this study, we present the results of proximal femoral nailing surgery performed for reverse obliquity intertrochanteric fractures using two lag screws, and include evaluation of the quality of the reduction, operative time, complications and functional status of the patients.

\section{Materials and Methods}

From Feb 2005 to Feb 2014, 53 patients with AO/OTA 31 A-A3 fractures were treated by proximal femoral nailing in our trauma centre. Our unit is familiar with the use of proximal femoral nailing for the treatment of all per trochanteric fractures. The mean age of our patients was 62 years (range 25 - 93 yrs). Twenty nine males and twenty four females were enrolled for the study. The mean follow up of our series was 12.1 months (range 12 60 months). The distribution of the fractures in our series is included in Table 1. The associated fractures in our series are included in Table 2.

All operations were performed within 6 days of injury under spinal anaesthesia. Informed consent of all the patients and approval of the Hospital ethics committee was taken. The patients were placed on the traction table

Table 1. The sex distribution and the fracture pattern in our series.

\begin{tabular}{ccc}
\hline & Male & Female \\
\hline A3.1 Simple, oblique & $7(13.2 \%)$ & $2(3.77 \%)$ \\
A3.2 Simple, transverse & $9(16.98 \%)$ & $11(20.75 \%)$ \\
A3.3 With a medial fragment & $13(24.52 \%)$ & $11(20.75 \%)$ \\
Total & $29(54.71 \%)$ & $24(45.28 \%)$ \\
\hline
\end{tabular}

Table 2. The associated fracture pattern in our series.

\begin{tabular}{ccc}
\hline Associated injuries in our series & Male & Females \\
\hline Vertebral compression fracture & 2 & 1 \\
Tibia and fibula fracture & 1 & \\
Fracture ribs & 2 & 1 \\
Shaft humerus & & 1 \\
Radius Ulna Fracture & 5 & 3 \\
\hline
\end{tabular}


and closed reduction was ascertained under image intensifier in AP and lateral views. Near anatomical closed reduction was achieved in 47 patients whereas six needed limited open reduction. A combination of $3^{\text {rd }}$ generation Cephalosporin and Amino glycoside was administered intravenously $30 \mathrm{~min}$. prior to the skin incision. The same combination was used for 48 hours postoperatively in standard doses. We had to resort to the use of the Schanz screws $(n=3)$ to help the fracture fragments in alignment and use of the clamps $(n=3)$ by a resorting to a mini incision. The amount of femoral bowing was determined and decision regarding the usage of the long proximal femoral nail was taken to prevent the nail impinging against the anterior femoral cortex in three cases.

The Proximal femoral nail of $250 \mathrm{~mm}$ used in this study was made of 316L stainless steel and the diameters used were $9 \mathrm{~mm}, 10 \mathrm{~mm}$ and $11 \mathrm{~mm}$. The neck shaft angle of 135 degrees was used in the forty eight patients whereas the rest needed a 130 degree nail. The nail accommodates a $6.5 \mathrm{~mm}$ hip derotation screw and a $8 \mathrm{~mm}$ femoral lag screw. A 4.9 distal locking screws to be used in the static and dynamic holes of the nails, and an end cap completes the assembly. The nail has a $13 \mathrm{~mm}$ proximal diameter. There is 6 degrees of mediolateral valgus angle, which prevent varus collapse of the fracture even when there is medial comminution and allows the ease of insertion. The distal diameter is tapered to 9 to $12 \mathrm{~mm}$ which also has grooves to prevent stress concentration at the end of the nail and avoids fracture of the shaft distal to the nail. The distal dynamic hole permits $5 \mathrm{~mm}$ dynamization.

The quality of reduction was considered as anatomical if there was less than 5 degrees of varus, valgus, anteversion or retroversion in the post reduction images seen on the Image intensifier. It was considered acceptable if the deviation was between 5 - 10 degrees and poor if it exceeded 10 degrees [6].

The ideal recommended screw tip position was in the inferior half of the femoral head as seen in the anteroposterior radiograph and in the centre part of the head in the lateral radiograph.

A $250 \mathrm{~mm} 135$ degree nail was used in 46 patients and a 130 degree nail in seven patients. A long PFN nail was used in three cases where we felt the femoral curvature was marked and the fracture line extended distally. All the nails were locked with two distal screws. The nails were passed according to the manufacturer's guidelines. No reaming was done to accommodate the nail.

The mean surgical time was 55 minutes. The mean estimated blood loss was $130 \mathrm{ml}$. Meticulous closure was done and no negative pressure suction drain was used. The average length of hospital stay was on average 7 days.

Active and passive exercises were initiated within 48 hrs of operation. Partial weight bearing under the guidance of physiotherapist was allowed in 40 patients after suture removal, and the rest were confined to mobilisation in bed. These were the patients who had additional injuries to their skeleton. Blood transfusion was needed for three patients who had a very low preoperative haemoglobin level.

In order to evaluate the accuracy of device placement and mechanical performance of the device, radiographic results were also analyzed according to tip-apex distance, amount of translation of the two hip screws and the degree of varus collapse at the time of final radiographic follow-up.

\section{Results}

All patients were evaluated by regular physical and radiographic examinations. Clinical and functional outcomes were assessed according to Harris hip score and Barthel activity score, respectively. Cut-out, Z-effect or reversed Z-effect of the lag screws were scored as technical failures. Postoperative radiographs showed a nearanatomical fracture reduction in $80 \%$ of patients. During a mean of 12.01 months (range $12-38$ months ) the results, as well as the intraoperative and postoperative complications, were noted.

The average union time was 11.5 weeks (range 11 - 18 weeks). Fractures were judged to be completely healed when osseous consolidation could be observed in two planes on plain radiographs on sequential follow up and pain-free ambulation was possible (Figure 1). The fractures healed in all patients. In three cases we could see the "Z" effect.

No perceptible shortening was noted. We had two cases of delayed union due to failure to reduce the abducted trochanteric fragment which remained separated. In three cases there was marked prominence of the hip screws which was felt on the lateral aspect of the thigh and interfered with the mobility as noted on the six monthly follow up (Figure 2). The patient refused revision for the same. In one patient, during the serial follow up, there was distal migration of the stabilising hip screw which got locked. But the fracture healed well without any complication (Figure 2). In one patient there was breakage of the distal interlocking bolt at 9 months, but the fracture united (Figure 3). 


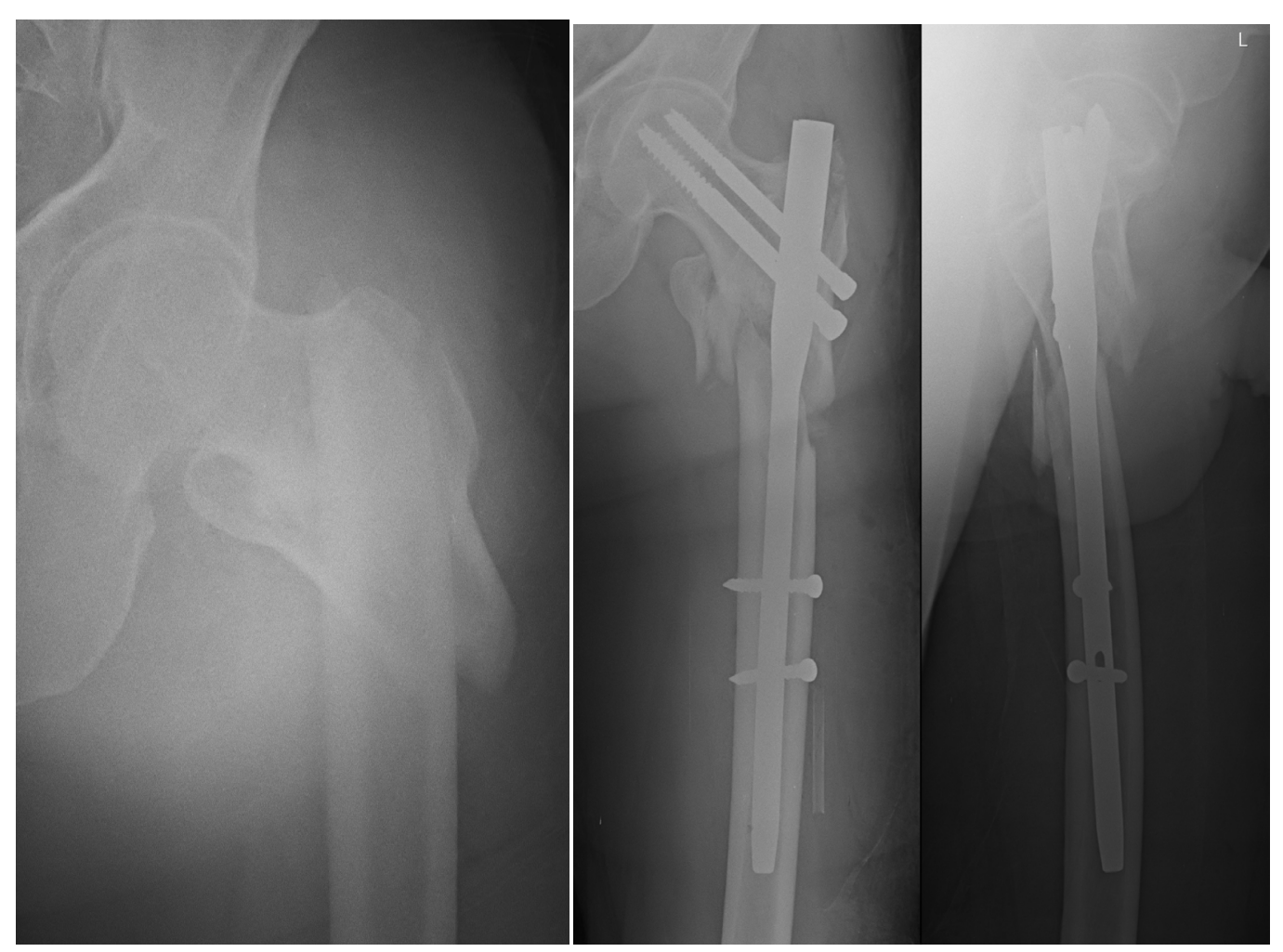

(a)

(b)

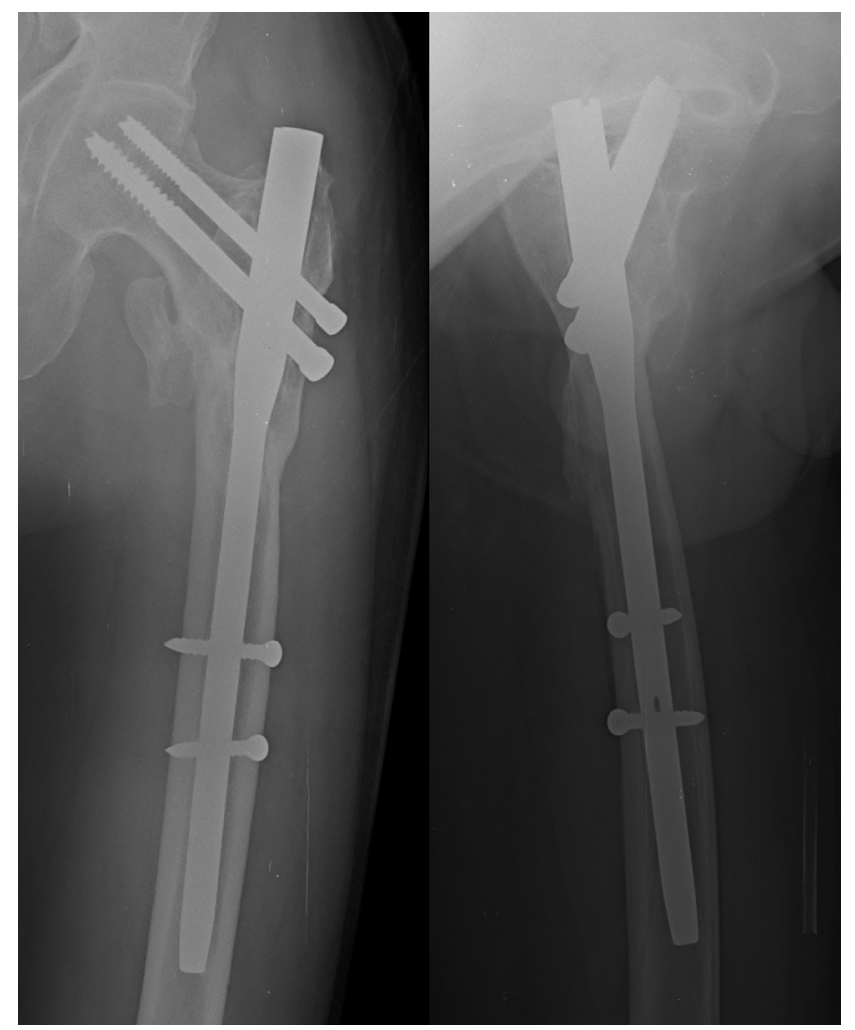

(c)

Figure 1. (a) Preoperative image of A3.3 fracture, (b) Immediate post operative image showing the well captured lateral trochanteric fragment with implant in situ, (c) showing the well healed fracture at eighteen months follow up. 


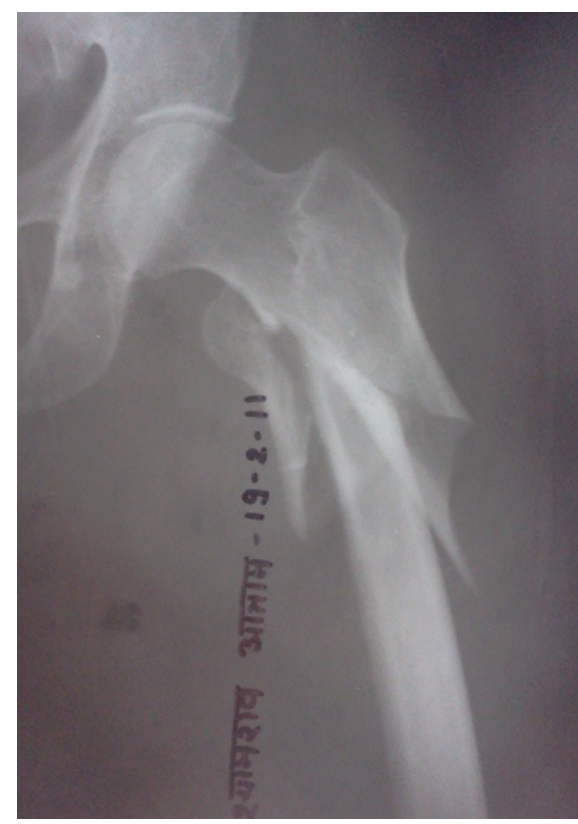

(a)

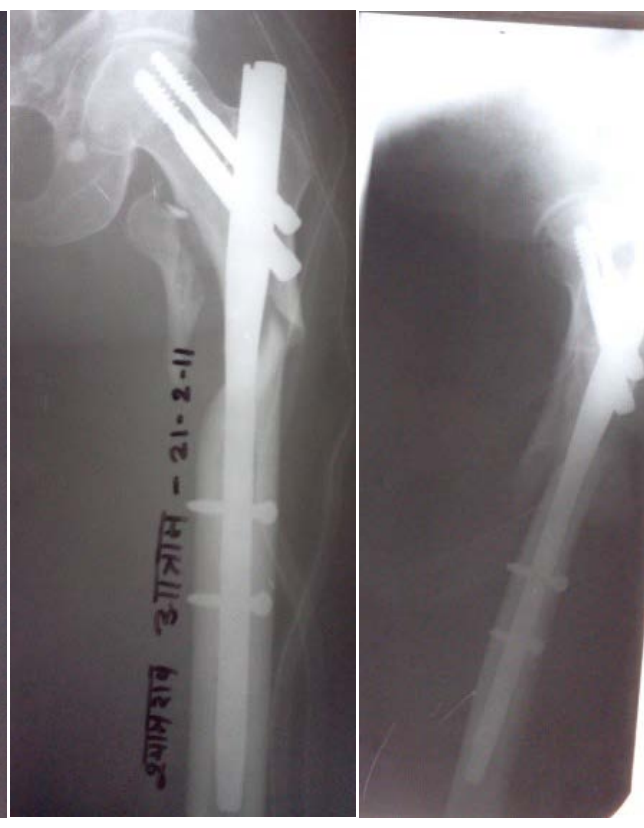

(b)

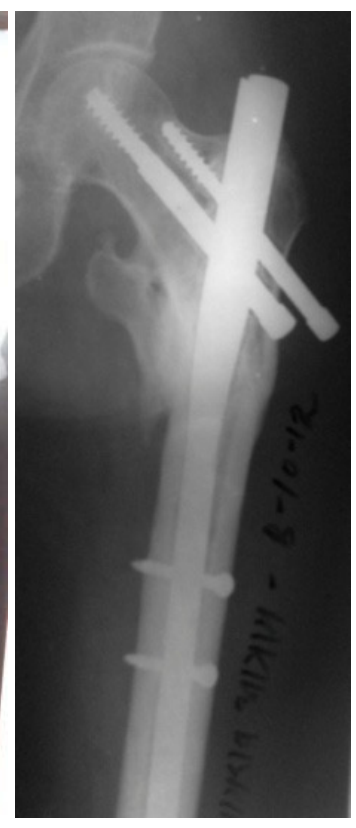

(c)

Figure 2. An unstable communited A3. 3 fracture fracture with loss of lateral and medial support (a) managed with PFN (b) showing good consolidation with distal migration of the stabilisation screw at eighteen months followup (c).

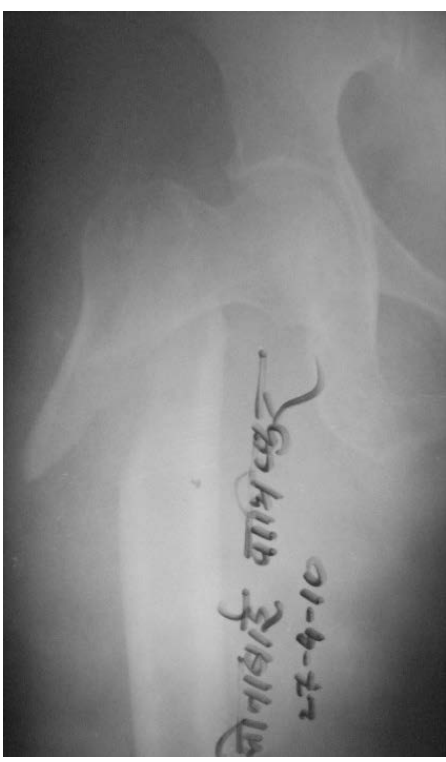

(a)

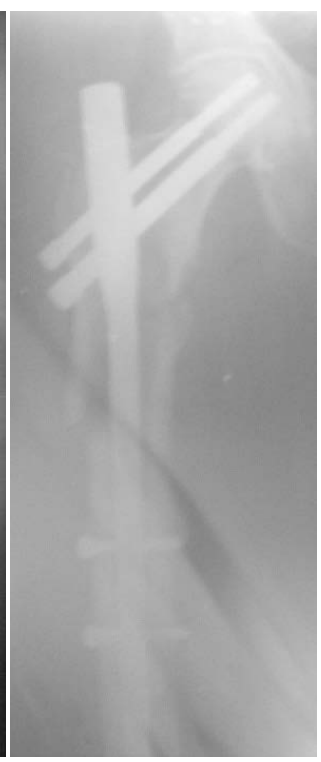

(b)

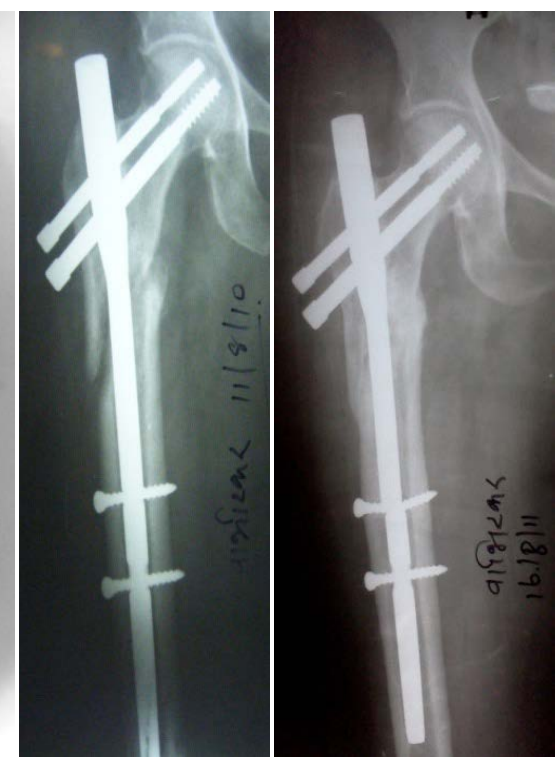

(c)

Figure 3. An unstable fracture (a) managed with PFN (b) showing progress of healing at 4 moths (c) and good consolidation with breakage of the static screw at 16 months (d).

Of the 53 patients, 3 had superficial infections which were controlled with antibiotics. One patients died due to unrelated medical conditions within 15 months of the follow up, and four patients (A3.1 $n=2$ and A3.2 n = 2) were lost to follow up after 11 months.

82\% had a full range of hip motion. The mean Harris hip score was 76.66 (range 70 - 93) and the mean Barthel activity score was 16.21 (range 12 - 20). Thirty Nine patients had excellent results, ten had good results and four had poor results according to Harris hip score. We had no intraoperative complications and no cortical hypertrophy at the level of the tip of the implant was noted during the radiological follow-up. 


\section{Discussion}

Trochanteric fractures are one of the most important causes of mortality and morbidity, especially in the elderly population. Reverse obliquity intertrochanteric fractures are unstable with unique anatomical and mechanical characteristics. The successful treatment of per trochanteric fractures depends on many factors such as the age of the patient, the patient's general health, the time from fracture to treatment, the adequacy of treatment, concurrent medical treatment, and the stability of fixation [7]. The implants have to satisfy the requirements and the hold the fracture till the clinico-radiological union is evident.

It is essential to understand the applied anatomy of the proximal femur especially in the zone where these fractures take place. The subtrochanteric region of the femur consists primarily of cortical bone. The femoral head and neck are anteverted approximately $10^{\circ}-15^{\circ}$ in relation to the plane of the femoral shaft. The piriformis fossa lies at the base of the neck and is oriented in line with the femoral shaft. The lesser trochanter is posteromedial, and it is the point of insertion for the psoas and iliacus tendons. The femoral shaft has both an anterior and a lateral bow. The major muscles that surround the hip create significant forces that contribute to fracture deformity. The gluteus medius and minimus tendons attach to the greater trochanter and abduct the proximal fragment. The psoas and iliacus attach to the lesser trochanter and flex the proximal fragment. The adductors pull the distal fragment medially. All of these muscles are well vascularized, and this can lead to torrential hemorrhage at the time of injury or during surgical approaches.

Haemodynamically stabilizing the patient and early surgical stabilisation of the fractures is important to decrease the mortality risk and reduce complications associated with long-term immobilisation [1] [2].

The sliding hip screw fixation for the reverse obliquity intertrochanteric fractures are fraught with complications like non union and implant failure. The weight on the fractured limb generates a shearing movement at the fracture side and results in telescoping of the implant which jeopardises the eventual functional outcome. These fractures therefore pose a great challenge to both patients and orthopaedic surgeons.

In the Norwegian hip fracture registry, the use of SHS and IM nail for transverse/reverse oblique trochanteric and subtrochanteric fractures were analysed. It was found that the number of re-operations for patients operated with a Sliding hip screw was significant. The results regarding pain, patient satisfaction, quality of life, and mobility were all slightly in favour of IM nailing [8].

The biomechanics of intramedullary fixation in the context of a destabilized medial cortex are optimized by medialization of the fulcrum point and resultant reduction of the bending moment with respect to proximal fixation [9]. Although the intramedullary fixation has a biomechanical advantage of shorter lever arm compared to extramedullary implants, clinical reports of intramedullary nailing for reverse obliquity and unstable fractures are very limited in number [6].

We found that using two proximal lag screws could provide better rotational control of the femoral head fragment and decrease the cut-out of the femoral head by prevention of toggling of the head fragment [7].

It is essential that the displaced fracture fragments should be brought in close approximation to each other considering the transition zone on the proximal femur where they occur. Dissection of periosteum is not always needed, and some minimally invasive techniques can be used to reduce blood loss. As precise reduction and strong fixation are the main objective of the operation, closed reduction may not be able to achieve this goal but an open reduction can.

Use of screws and circlage wire is recommended to appose the fragments in addition to the cephalomeduallary devices [10] [11]. In fractures with long spike we resorted to cerclage wire fixation of the fragments taking care to preserve blood supply and avoiding damage to the periosteum, which is the integral part for bone healing, by using the circle wire passer. We never hesitated for mini incision open reduction and used clamps, as have been advocated [12]. In the early part of our series where the fragments were not brought in apposition by the above mentioned techniques, the fracture healed with marked callus and the union was delayed.

The greater trochanter fragment and the lateral trochanteric wall play an important role in stability after implant fixation of pertrochanteric fractures as has been stressed by Gotfried [13]. The broken lateral trochanteric wall should be engaged in the proximal screws supplemented with the use of the washer.

The proximal lateral femur locking plates (PFLCP) can be a feasible alternative for the treatment of such unstable pertrochanteric fractures because it provides proper fixation of the lateral fragments and prevents the lateral migration of proximal fragments. Open reduction of proximal femur causes blood loss and requires proficient technique [14]. As the screws of PFLCP lock with the plate, the system behaves like an external fixator 
frame, which can hold all the major fragments without lateral stress on the greater trochanter fragment [15].

In A3 fractures, unlike the A1 and A2 fractures, impaction by the axial loading does not occur, and medial displacement of the distal fragment of the fracture is common due to the intrinsic instability [16].

Sadowski et al. [17] showed in their prospective randomized trial in patients with a reverse obliquity or transverse intertrochanteric fracture who were randomized to either a 95 degree screw-plate or cephalomedullary nail a much higher failure rate for the plate-screw implant. Implant failure was seen in seven of the 19 patients treated with the 95 degree screw plate and whereas only1 patient in Intramedullary nail group had a failure.

The Russell-Taylor reconstruction nail is also being used satisfactorily for the fixation in complex and unstable proximal femoral injuries, but we have no experience with the usage of this nail [18].

For a stable fixation and to prevent varus collapse of the femoral head it is important to place the inferior lag screw as close as possible to the inferior femoral neck cortex on AP view and both screws as close as possible to the central part of the femoral head [6].

The PFN nail in per trochanteric fractures has been shown to prevent the fractures of the femoral shaft by having a smaller distal shaft diameter and fluting of the tip of the nail. The PFN has a greater implant length extending unto the distal femur, a smaller valgus angle, and this angle is set at a higher level and the more proximal positioning of the distal locking helps to avoid abrupt changes in the stiffness of the construct [19].

Due to its position close to the weight-bearing axis the stress generated on the intramedullary implants is negligible. The PFN acts as a buttress in preventing the medialisation of the shaft. The entry portal of the PFN through the trochanter limits the surgical insult to the tendinous hip abductor musculature only [20], unlike those nails which require entry through the pyriformis fossa.

The stabilising and the compression screws of the PFN adequately compress the fracture, leaving between them a bone block for further revision should the need arise [7]. As the amount of iatrogenic soft tissue insult is minimal the use of PFN in the treatment of pertrochanteric fractures may have positive effect on the speed at which walking is restored. We strongly advocate a meticulous closure of the soft tissue and stress the importance of physiotherapy in the post operative period.

Limitations of our study are lack of control group and relatively small patient population. One has to appreciate the fact that these fractures account for $5 \%-23 \%$ of all trochanteric fractures even in the higher trauma centres and limited number of publications endorse the fact [6] [20].

We stress the fact that proximal femoral nail may be a good option in the treatment of reverse oblique trochanteric fractures if attention is given to ensure correct technique during nail insertion. Reduction of the fracture should be the priority before passing the intramedullary nail. The correct entry point for the nail, that is, the tip of the greater trochanter on the anteroposterior and in line with the femoral neck on the lateral view, should be achieved. It is better to err by going a bit medial rather than shifting the entry point laterally. Care should be taken to avoid distraction during insertion of the nail. Consideration regarding the anterior bowing of the femoral shaft should be determined preoperatively to avoid penetration the anterior femoral cortex. Provision for the long PFN should be available in case of inadvertent penetration of the femoral shaft. The majority of these implants are used in the elderly who have a baseline susceptibility to recurrent falls in the setting of decreased bone mineral density and are at risk for femoral re-fracture around the implant regardless of its length.

It had been proven in other studies that the rate of re-operation, 1-year mortality rate, union rate and functional status and mobility does not differ regarding the usage of either the short or long PFN [21]. We feel that the standard PFN is indicated for more proximal fractures, whereas the long PFN for more the distal fractures. It is at the subtrochantericextension of the fractures where there is an overlap in the choice of the implant [22].

We believe that the geriatric fractures with capacious, osteoporotic medullary canals, need angular stability which the interlocking screws might provide and help to decrease their pain.

The use of PFN prevents the rotation of the head/neck fragment [23]. It prevents the rotations until fracture healing. Despite correct technical application, complications such as varus angulation of the proximal fragment and medialisation of the distal fragment during nail insertion, which may necessitate open reduction, may occur. The presence of a second proximal neck screw in PFN may increase rotational stability of the cervico-cephalic fragments. They provide the much needed stability for the healing [7] facilitating early postoperative rehabilitation. It is essential that the fracture fixation should not be in varus as it causes excessive loads on the implants and a possibility of implant failure [24].

We strongly feel that PFN is a good implant for the management of the reverse trochanteric fractures if the attention is paid to the technical details, the soft tissue is meticulously handled and patience kept to master the 
art of skilful nailing.

The limitations of this study we feel are a relatively small sample size and the adherence to one single implant type i.e. PFN. Though there have been studies that have shown good outcomes with other cephalomedullary implants, the consensus for the management of such challenging injuries we feel lies solely on the intramedullary devices. We feel that the prospective functional outcome studies of elderly patients with reverse trochanteric fractures are needed to determine if the theoretical advantages of the various intramedullary implants warrant their routine clinical use. A much larger cohort of study population shall guide to arrive at a consensus.

\section{References}

[1] Domingo, L., Cecillia, D., Herrera, A., et al. (2001) Trochanteric Fractures Treated with a Proximal Femoral Nail. International Orthopaedics, 25, 298-301. http://dx.doi.org/10.1007/s002640100275

[2] Haldar, S.C. (1992) The Gamma Nail for Pertrochanteric Fractures. The Journal of Bone \& Joint Surgery, 74-B, 340344.

[3] Leung, K.S., So, W.S., Shen, W.Y., et al. (1992) Gamma Nails and Dynamic Hip Screws for Pertrochanteric Fractures. The Journal of Bone \& Joint Surgery, 74-B, 345-351.

[4] Banan, H., Al-Sabti, A., Jimulia, T. and Hart, A.J. (2002) The Treatment of Unstable Extracapsuler Hip Fractures with AO/ASIF Proximal Femoral Nail (PFN)_Our First 60 Cases. Injury, 33, 401-405. http://dx.doi.org/10.1016/S0020-1383(02)00054-2

[5] Boldin, C., Seibert, F.J., Frankhauser, F., et al. (2003) The Proximal Femoral Nail (PFN)—A Minimal Invasive Treatment of Unstable Proximal Femoral Fractures: A Prospective Study of 55 Patients with a Follow-Up of 15 Months. Acta Orthopaedica Scandinavica, 74, 53-58. http://dx.doi.org/10.1080/00016470310013662

[6] Ozkan, K., Eceviz, E., Unay, K., et al. (2011) Treatment of Reverse Oblique Trochanteric Femoral Fractures with Proximal Femoral Nail. International Orthopaedics, 35, 595-598. http://dx.doi.org/10.1007/s00264-010-1002-z

[7] Gadegone, W.M. and Salphale, Y.S. (2007) Proximal Femoral Nail—An Analysis of 100 Cases of Proximal Femoral Fractures with an Average Follow up of 1 Year. International Orthopaedics, 31, 403-408. http://dx.doi.org/10.1007/s00264-006-0170-3

[8] Matre, K., Havelin, L.I., Gjertsen, J.E., Vinje, T., Espehaug, B. and Fevang, J.M. (2013) Sliding Hip Screw versus IM Nail in Reverse Oblique Trochanteric and Subtrochanteric Fractures. A Study of 2716 Patients in the Norwegian Hip Fracture Register. Injury, 44, 735-742. http://dx.doi.org/10.1016/j.injury.2012.12.010

[9] Rosenblum, S.F., Zuckerman, J.D., Kummer, F.J. and Tam, B.S. (1992) A Biomechanical Evaluation of the Gamma Nail. The Journal of Bone and Joint Surgery, British Volume, 74, 352-357.

[10] Hoskins, W., Bingham, R., Joseph, S., Liew, D., Love, D., Bucknill, A., Oppy, A. and Griffin, X. (2015) Subtrochanteric Fracture: The Effect of Cerclage Wire on Fracture Reduction and Outcome. Injury, 46, 1992-1995. http://dx.doi.org/10.1016/j.injury.2015.07.001

[11] Müller, T., Topp, T., Kühne, C.A., Gebhart, G., Ruchholtz, S. and Zettl, R. (2011) The Benefit of Wire Cerclage Stabilisation of the Medial Hinge in Intramedullary Nailing for the Treatment of Subtrochanteric Femoral Fractures: A Biomechanical Study. International Orthopaedics, 35, 1237-1243. http://dx.doi.org/10.1007/s00264-010-1204-4

[12] Afsari, A., Liporace, F., Lindvall, E., Infante Jr., A., Sagi, H.C. and Haidukewych, G.J. (2010) Clamp-Assisted Reduction of High Subtrochanteric Fractures of the Femur: Surgical Technique. The Journal of Bone and Joint Surgery, American Volume, 92, 217-225.

[13] Gotfried, Y. (2007) Integrity of the Lateral Femoral Wall in Intertrochanteric Hip Fractures: An Important Predictor of a Reoperation. The Journal of Bone and Joint Surgery, American Volume, 89, 2552-2553.

[14] Hu, S.-J., Zhang, S.-M. and Yu, G.-R. (2012) Treatment of Femoral Subtrochanteric Fractures with Proximal Lateral Femur Locking Plates. Acta Ortopédica Brasileira, 20, 329-333. http://dx.doi.org/10.1590/S1413-78522012000600003

[15] Egol, K.A., Kubiak, E.N., Fulkerson, E., Kummer, F.J. and Koval, K.J. (2004) Biomechanics of Locked Plates and Screws. Journal of Orthopaedic Trauma, 18, 488-493. http://dx.doi.org/10.1097/00005131-200409000-00003

[16] Kregor, P.J., Obremsky, W.T., Kreder, H.J. and Swiontkowski, M.F. (2005) Evidence-Based Orthopaedic Trauma Working Group. Unstable Pertrochanteric Femoral Fractures. Journal of Orthopaedic Trauma, 19, 63-66. http://dx.doi.org/10.1097/00005131-200501000-00014

[17] Sadowski, C., Labbeke, A., Saudan, M., Riand, N., Stern, R. and Hoffmeyer, P.J. (2002) Treatment of Reverse Oblique and Transverse Intertrochanteric Fractures with Use of an Intramedullary Nail or a 95 Degrees Screw-Plate: A Prospective, Randomized Study. The Journal of Bone \& Joint Surgery, 84-A, 372-381.

[18] Garnavos, C., Peterman, A. and Howard, P. (1999) The Treatment of Difficult Proximal Femoral Fractures with the Russell-Taylor Reconstruction Nail. Injury, 30, 407-415. http://dx.doi.org/10.1016/S0020-1383(99)00107-2 
[19] Korkmaz, M.F., Erdem, M.N., Disli, Z., Selcuk, E.B., Karakaplan, M. and Gogus, A. (2014) Outcomes of Trochanteric Femoral Fractures Treated with Proximal Femoral Nail: An Analysis of 100 Consecutive Cases. Clinical Interventions in Aging, 9, 569-574.

[20] Park, S.Y., Yang, K.H., Yoo, J.H., Yoon, H.K. and Park, H.W. (2008) The Treatment of Reverse Obliquity Intertrochanteric Fractures with the Intramedullary Hip Nail. The Journal of Trauma, 65, 852-857. http://dx.doi.org/10.1097/TA.0b013e31802b9559

[21] Okcu, G., Ozkayin, N., Okta, C., Topcu, I. and Aktuglu, K. (2013) Which Implant Is Better for Treating Reverse Obliquity Fractures of the Proximal Femur: A Standard or Long Nail? Clinical Orthopaedics and Related Research, 471, 2768-2775. http://dx.doi.org/10.1007/s11999-013-2948-0

[22] Ongkiehong, B.F. and Leemans, R. (2007) Proximal Femoral Nail Failure in a Subtrochanteric Fracture: The Importance of Fracture to Distal Locking Screw Distance. Injury Extra, 38, 445-450. http://dx.doi.org/10.1016/j.injury.2007.03.015

[23] Sommers, M.B., Roth, C., Hall, H., et al. (2004) A Laboratory Model to Evaluate Cut out Resistance of Implants for Pertrochanteric Fracture Fixation. Journal of Orthopaedic Trauma, 18, 361-368. http://dx.doi.org/10.1097/00005131-200407000-00006

[24] Marmor, M., Liddle, K., Buckley, J. and Matityahu, A. (2016) Effect of Varus and Valgus Alignment on Implant Loading after Proximal Femur Fracture Fixation. European Journal of Orthopaedic Surgery \& Traumatology, 26, 379383. http://dx.doi.org/10.1007/s00590-016-1746-2

\section{Submit or recommend next manuscript to SCIRP and we will provide best service for you:}

Accepting pre-submission inquiries through Email, Facebook, Linkedin, Twitter, etc A wide selection of journals (inclusive of 9 subjects, more than 200 journals)

Providing a 24-hour high-quality service

User-friendly online submission system

Fair and swift peer-review system

Efficient typesetting and proofreading procedure

Display of the result of downloads and visits, as well as the number of cited articles

Maximum dissemination of your research work

Submit your manuscript at: http://papersubmission.scirp.org/ 